\title{
Ferramentas Digitais para a Interação Assíncrona: análise de aplicações
}

\author{
Francieli Ludovico $^{1}$, Aline Machado ${ }^{1}$, Augusto Weiand ${ }^{1}$, Patrícia Costa Barcellos ${ }^{1}$ \\ ${ }^{1}$ Programa de Pós-Graduação em Informática na Educação - Universidade Federal do \\ Rio Grande do Sul (UFRGS) - Porto Alegre - RS - Brazil \\ francielimeutfpr.edu.br, aline.dubaleosorio.ifrs.edu.br, \\ guto.weiandegmail.com, patrícia.campelo@ufrgs.br
}

\begin{abstract}
Resumo. O presente trabalho teve como intuito, analisar a aplicação de quatro ferramentas digitais utilizadas em aulas a distância de forma assíncrona em uma disciplina de pós-graduação para verificar a promoção da interação. Esse estudo, metodologicamente, seguiu pelos caminhos da pesquisa qualitativa, de tipo pesquisa-ação. Constatou-se que todas as ferramentas possibilitaram interação, no entanto, apenas em duas práticas a Interação Potencializada ocorreu, viabilizando, assim, práticas educacionais com mediação em prol de uma aprendizagem significativa e social.
\end{abstract}

\begin{abstract}
The present work aimed to analyze the application of four digital tools used in distance classes asynchronously in a postgraduate course to verify the interaction promotion. This study, methodologically, followed the qualitative perspective focusing on action research. It was verified that all tools enabled interaction, however, in only two practices Potential Interaction occurred, thus enabling educational practices with mediation in favor of meaningful and social learning.
\end{abstract}

\section{Introdução}

A Educação a Distância (EaD) na Web 1.0 era a "de um para muitos" [Rojo, 2017, p.8], de transmissão de conhecimento, a Web 2.0 permitiu a promoção da interação, e a Web 3.0 acrescenta a personalização. Oferecendo oportunidades de socialização e por meio desse processo há mediação entre sujeitos, contribuindo, assim, para aprenderem e desenvolverem-se como sujeitos socioculturais.

A interação é a base para que ocorra o processo de trocas e construções no meio digital. Logo, em tempos de EaD é primordial possibilitar práticas significativas para otimizar os processos de ensino e aprendizagem e encurtar distâncias. As ferramentas e ambientes digitais são recursos que potencializam a interação, sabendo que essa é a ação necessária para a promoção da mediação na $\mathrm{EaD}$, pois, é na interação que o sujeito dá sentido ao mundo que o cerca, compreendendo-o e agindo sobre ele.

A interação na $\mathrm{EaD}$ geralmente é promovida por meio de fóruns, chat e wikis, mas existem outros caminhos para possibilitar interação. Nesse sentido, o objetivo do presente estudo foi analisar a aplicação de ferramentas digitais utilizadas em aulas a distância de forma assíncrona em uma disciplina de pós-graduação, com intuito de verificar a promoção da interação. 
VIII Congresso Brasileiro de Informática na Educação (CBIE 2019)

Anais dos Workshops do VIII Congresso Brasileiro de Informática na Educação (WCBIE 2019)

\section{Tecnologia em interface de interação e mediação}

As tecnologias e suas interfaces permitem o exercício da práxis docente e experiências variadas em prol do aprendizado e constituição do estudante e, assim, ao se utilizar objetos e ambientes digitais na educação, abre-se uma gama de possibilidades para se impulsionar um processo de ensino. Então, cabe compreender como se dá a interação num contexto digital, visto que este conceito será configurado num tempo e espaço para além do tradicional de uma sala de aula.

É por meio da interação que o homem se torna homem, pois tem acesso à cultura, à língua e ao conhecimento que o tornam homem como ser social. Assim, compreende-se os pressupostos da teoria Vygotskyana (1998), a qual conceitua o termo interação que é central para o presente estudo. Os fundamentos sócio-interacionistas atribuem ao meio e pela interação a constituição de cada pessoa. Logo, no âmbito educacional, a interação social promove a potencialidade do homem, pois é pela troca social, de cultura, de língua, de informações e no processo de aprendizagem que cada um desenvolve suas capacidades e habilidades. Com isso, infere-se como elemento fundamental para a interação a mediação que se dá através de instrumentos e signos.

A aprendizagem do homem se dá pelo uso desses instrumentos e signos como base externa que possibilita a mediação em diferentes contextos e, assim, os signos que são de natureza cultural e convencionados no social possibilitam que os sujeitos interajam socialmente através do domínio desses e a linguagem se faz, como um grande sistema de mediação instrumental [Vygotsky, 1998].

A interação por meio da linguagem gera diferentes possibilidade de trocas e novas construções entre os sujeitos e, diante disso, numa ação pedagógica em contexto tecnológico promove-se as trocas interpessoais entre os sujeitos, bem como a interação de cada um com as ferramentas em uso. As possibilidades de interação disponibilizadas por uma prática educacional digital com diferentes ferramentas otimizam a mediação e influenciam no processo de aprendizagem.

A WEB 2.0 traz possibilidades com potencial de compartilhamento, os usuários produzem conteúdos em postagens e publicações, é interativa, surgem as redes sociais e redes de mídia [Rojo e Barbosa, 2015]. Abre espaço para a participação, colaboração e interação de todos. Dessa forma, a Educação a Distância também ganha espaço, podendo reconfigurar-se para promover aprendizado e participação ativa.

As quatro ferramentas digitais ${ }^{1}$ utilizadas nesse trabalho e descritas a seguir, baseiam-se nesses preceitos, assim como, possibilitam aos usuários a criação e apresentação de conteúdos hipermidiáticos, multimodais de maneira colaborativa, assíncrona, de modo a possibilitar a sua utilização de forma atemporal. Todas ferramentas aqui descritas foram utilizadas em suas versões gratuitas, apesar de disponibilizarem uma paga, com maior número de recursos.

O VoiceThread (VT) é uma ferramenta de apresentação de slides multimídia interativa, possibilita que os usuários mantenham conversas em torno de imagens, documentos e vídeos, permitindo que os alunos participem e colaborem de várias

\footnotetext{
${ }^{1}$ Voice Thread: https://voicethread.com/ - Google Apresentações: https://www.google.com/slides/about/ Nearpod: https://nearpod.com/ - Padlet: https://pt-br.padlet.com/
} 
maneiras em seu próprio ritmo [Brunvand, 2011]. O Google Apresentações (GA) possibilita, assim como o VT um ambiente de criação de slides hipertextuais com recursos multimídia e integração com serviços da própria empresa, de modo a facilitar o seu uso [Ramos et. al., 2017]. As interações possíveis para as apresentações são baseadas apenas no formato de comentários escritos nos próprios slides.

De forma semelhante ao GA, o software Nearpod $(\mathrm{N})$, consiste em uma abordagem de slides multimodais onde pode-se compartilhar apresentações interativas com os autores/leitores, indo além da hipertextualidade possibilitando a inserção de quizzes, sondagens, e painéis interativos, por exemplo [Caetano e Nascimento, 2019].

Diferentemente dos softwares já descritos, Padlet $(\mathrm{P})$ constitui-se em um mural online e colaborativo que possibilita aos autores/leitores curtir e comentar materiais disponibilizados por ambos no mesmo ambiente. Esses materiais constituem-se de recursos hipermidiáticos, que vão desde textos simples à links de internet como vídeos, mapas, websites, etc [Silva e Lima, 2018].

\section{Metodologia}

A presente pesquisa é sustentada pela abordagem qualitativa caracterizada como pesquisa-ação. As práticas aqui analisadas ocorreram em uma disciplina semipresencial de pós-graduação com os mesmos participantes, sete alunos e professor. Para cada aula a distância uma dupla de alunos ficou responsável por promover a atividade assíncrona. A proposta foi realizar a exposição do texto e promoção de interação por meio de alguma ferramenta digital. As opções pelas ferramentas ficaram à escolha das duplas. Após as apresentações, foram coletados dados relativos às interações nessas ferramentas e proposta a discussão acerca dessas e do potencial de uso de cada uma.

\section{Análise das Práticas de Interação com Diferentes Ferramentas Digitais}

Nesse estudo é proposta a análise de quatro ferramentas digitais utilizadas em aulas assíncronas: VT, GA, N e P. A análise das interações aconteceu a partir de três categorias, sendo elas: Interação Potencializada (IP): quando um comentário promove outros, e isso proporciona mais experiências mediadoras que influenciam significativamente no processo de aprendizagem. Interação Pouco Potencializada (IPP): o sujeito que está interagindo com a ferramenta, faz relações com o conteúdo e gera sua interação, mas não instiga outros para a discussão, pode significar a reflexão e construção de conhecimento de forma individual. Interação Não Potencializada (INP): quando no uso da ferramenta o sujeito não faz comentários ou apenas curte, como forma de feedback que não significa compreensão e não garante a mediação, mas, mesmo sem aparecer, a interação, do sujeito com a ferramenta, pode ser aprendizado.

A aula com a ferramenta VT promoveu muitas IP, algumas IPP e não houve INP, pois todos os participantes participaram das discussões e mostraram estar interagindo. A socialização, a partir dos comentários e reflexões possibilitou trocas, diálogos e gerou interação, o que segundo Vygotsky (1998) é primordial para o processo de aprendizagem.

$\mathrm{Na}$ prática com a ferramenta GA a maioria das interações foram INP, os participantes usaram o material com o objetivo de leitura. Em contrapartida, ocorreu o registro de algumas IP, mostrando que esse software possibilita diferentes negociações de interação. Já, os sujeitos que não participaram de IP não obtiveram mediação, mas 
VIII Congresso Brasileiro de Informática na Educação (CBIE 2019)

Anais dos Workshops do VIII Congresso Brasileiro de Informática na Educação (WCBIE 2019)

podem ter utilizado o material na ferramenta como instrumento de auxílio ao processo de aprendizagem.

Nas práticas com os softwares N e P ocorreram IPP e INP. Assim, pode-se observar que as interações aconteceram entre sujeito e ferramenta, não desenvolveu-se trocas interpessoais, visto que, para a teoria que ampara esse estudo, as trocas sociais são fundamentais para se gerar aprendizagem e construção pessoal.

\section{Considerações Finais}

A interação é considerada ação potencializadora nos processos de ensino e aprendizagem a distância, assim, as ferramentas digitais podem auxiliar na promoção de práticas educacionais significativas. Com base no uso dos referidos recursos, pode-se verificar que todos propiciaram interação, em diferentes níveis. No entanto, apenas na prática com VT e com GA a Interação Potencializada foi possível. Na análise desse grupo de sujeitos, a prática com o VT foi o que possibilitou maiores processos de mediação e aprendizagem. Nas práticas aqui relatadas a interação ocorreu de uma maneira, mas essas ferramentas podem promover diferentes resultados em outros momentos, pois existem outros fatores que influenciam a interação, como contexto, conteúdo, momento atual do sujeito, conhecimento de mundo, tempo, entre outros. Observou-se, ainda, que a interação nas aulas a distância foi importante para o desenvolvimento da disciplina.

\section{Agradecimentos}

Agradecemos ao IFRS - Osório pela concessão de licença capacitação e horário especial de estudante para os autores Aline e Augusto, respectivamente. Agradecemos, também, a UTFPR - Dois Vizinhos pela concessão de licença capacitação para a autora Francieli.

\section{Referências}

BRUNVAND, S.; BYRD, S. (2011) "Using VoiceThread to promote learning engagement and success for all students" In: Teaching exceptional children, v 43 n 4.

CAETANO, L. M. D.; NASCIMENTO, M. M. N. (2019) "Uso do App Nearpod no Ensino de História”. Olhares \& Trilhas, v 21, n 1.

RAMOS, R. C. G.; RAMOS, S. T. M., ASEGA, F. K. (2017) “GOOGLE DRIVE: Potencialidades para o design de material educacional digital (MED) para ensino de línguas”. In: The ESPecialist: Descrição, Ensino e Aprendizagem, v 38 n 1.

ROJO, R. (2017) "Entre Plataformas, ODAS e Protótipos: Novos Multiletramentos em Tempos de WEB2". In: The ESPecialist: Descrição, Ensino e Aprendizagem v38 n 1.

ROJO, R.; BARBOSA, J. (2015) "Gêneros do discurso, multiletramentos e hipermodernidade". In: ROJO, R.; BARBOSA, J. Hipermodernidade, multiletramentos e gêneros discursivos. SP: Parábola Editorial.

SILVA, P. G.; LIMA, D. S. (2018) "Padlet como Ambiente Virtual de Aprendizagem na Formação de Profissionais da Educação". In: RENOTE, v 16 n 1.

VYGOTSKY, L. S. (1998) “Pensamento e linguagem”. 2. ed. SP: Martins Fontes. 